\title{
Erratum to: A Well-Behaved Index of a Priori P-Power for Simple $N$-Person Games
}

\author{
Dan S. Felsenthal ${ }^{1,2}$
}

Published online: 18 November 2016

(C) Springer International Publishing Switzerland 2016

\section{Erratum to: Homo Oecon (2016) DOI 10.1007/s41412-016-0031-2}

Unfortunately the original publication contains a misprint in Sect. 4.7, lines 6-7: Instead of "Thus, for example, for the WVG $[51 ; 48,48,2]$ the smallest isomorphic WVG is $[2 ; 1,1,1]$."

it must read "Thus, for example, for the WVG [50; 48, 48, 2] the smallest isomorphic WVG is $[2 ; 1,1,1] . "$

\footnotetext{
The online version of the original article can be found under doi:10.1007/s41412-016-0031-2.
}

Dan S. Felsenthal

msdanfl@mail.huji.ac.il

1 School of Political Sciences, University of Haifa, 199 Abba Hooshi Boulevard, Mount Carmel, 3498838 Haifa, Israel

2 Voting Power and Procedures Programme, London School of Economics and Political Science, London, England, UK 